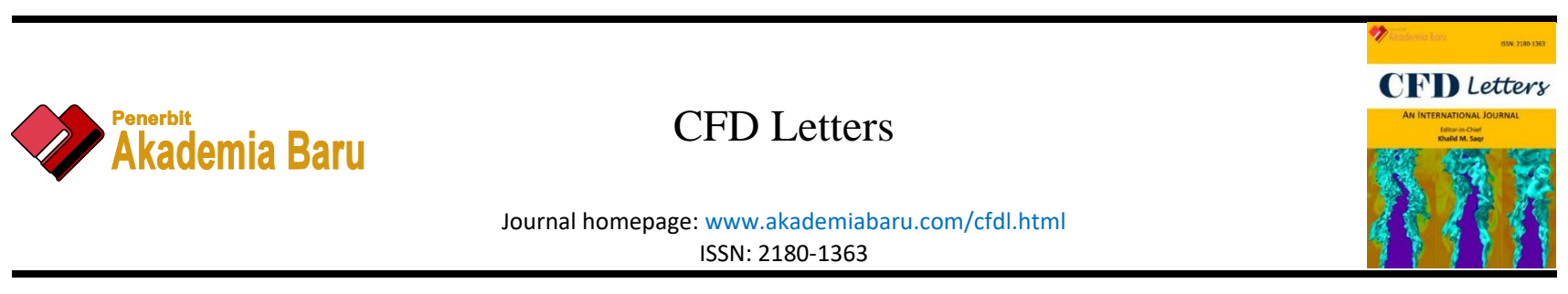

\title{
Study on the Addition of Nanoparticles in the Lead-free Solder During Reflow Soldering via Numerical Simulation - A Review
}

\author{
Intan Norshalina Sahrudin ${ }^{1}$, Mohd Sharizal Abdul Aziz ${ }^{1,{ }^{*}}$, Mohd. Zulkifly Abdullah ${ }^{1}$, Mohd Arif \\ Anuar Mohd Salleh² \\ 1 School of Mechanical Engineering, Universiti Sains Malaysia, 14300 Nibong Tebal, Penang, Malaysia \\ 2 Center of Excellence Geopolymer and Green Technology (CEGeoGTech), School of Materials Engineering, Universiti Malaysia Perlis (UniMAP), \\ Perlis, Malaysia
}

\section{ARTICLE INFO ABSTRACT}

Article history:

Received 19 March 2020

Received in revised form 18 May 2020

Accepted 23 May 2020

Available online 31 May 2020

\begin{abstract}
Surface mount technology (SMT) is a method of electronic components mounting or placed directly on the surface of the circuit board. The solder will be printed onto the substrate on the printed circuit board (PCB) and then undergoes reflow soldering process. As the used of lead $(\mathrm{Pb})$ is restricted by the restriction of hazardous substances (RoHS) directive in 2006 and Waste Electrical and Electronic Equipment (WEE), the study on the addition of nanoparticles into the lead-free solder has increased as to increase the reliability and quality of the lead-free solder. Researchers have added Cobalt, Silver, Molybdenum, Diamond, Silicon, Zinc, Zinc oxide and many more to increase few solder criteria such as the wetting properties, mechanical properties and the intermetallic compound (IMC) layers. Many numerical simulation methods such as finite element (FEM), finite volume (FVM), Lattice Boltzmann method (LBM), discrete phase method (DPM), and molecular dynamic (MD) simulation have been used to clearly show the reflow soldering process and to cut the cost of experimental work.
\end{abstract}

Copyright @ 2020 PENERBIT AKADEMIA BARU - All rights reserved

Keywords:

Lead-free solder; nanoparticle; reflow

soldering process; numerical simulation

\section{Introduction}

Surface-mount technology (SMT) has grown faster due to the increase of the customer requirement for electrical and electronic appliances. Lee [1] in his book, emphasized that SMT has existed in the mid of the 1960s, but not prevail for about 15 years. The evolution of SMT which is a method of mounting the electronic components directly onto the surface of the printed circuit board (PCB) is caused by its versatility of soldering and its cost-effective that will give advantages and a better level of performance for the small-scale or large-scale-manufacturing processes [2]. According to Yang [3], the reflow soldering is the best for SMT as the flux spraying step is not required due to the flux existence in the solder paste itself when compared with wave soldering. This process involves heating which will melt the solder paste, and then the components will be mounted onto the contact

\footnotetext{
* Corresponding author.

E-mail address: msharizal@usm.my (Mohd Sharizal Abdul Aziz)
} 
pad. The reflow soldering process is commonly done by using reflow oven, which undergoes four basic stages including preheat, thermal soak, reflow, and cooling and thus will ensure the components to be attached securely on the printed circuit board (PCB). After conducting several studies on the replacement of $\mathrm{Pb}$ solder, researchers found out $\mathrm{Sn}-\mathrm{Ag}-\mathrm{Cu}$ (SAC) lead-free solders are considered as a potential substitution of $\mathrm{Pb}-\mathrm{Sn}$ solder alloys $[4,5]$.

\section{Addition of Nanoparticles in Lead-free Solder Paste}

The study on the nano-composite solder paste has started in 2005 and published in 2007 where the lead-free solder was reinforced with polyhedral oligomeric silsesquioxanes (POSS) tri-silanols and from the result, the mechanical properties of the nano-reinforced solder paste give good increment in shear strength but still maintaining the overall toughness [6].

In the recent 10 years before, the research on the nano-reinforced solder paste becomes more vigorously as researchers found out that adding nanoparticles such as cobalt [7], copper [8-10], silver [11], nickel [12-15], diamond [16], the molecule of iron nickel oxide [17], iron oxide [18], titanium dioxide [19-21], zinc oxide [22] and others into the solder paste is proven to increase the solder properties in terms of either one, mechanical, thermal, wetting and intermetallic compound layer or all of them.

\section{Numerical Approaches on the Surface Mount}

Numerical approaches are introduced in the SMT field to reduce the cost and time-consuming experimental work. This approaches also make ease for showing the reaction of the solder in certain condition clearly and accurately. Over the years, there are lots of numerical approaches to simulate the reflow soldering process environment including FEM, FVM, LBM, and the newest one is DPM.

\subsection{Finite Element Method to Simulate the Reflow Soldering Process}

In the early 1960s Clough which is one of the founders and has formulated the finite element method through his book entitled "The Finite Element Method in Plane Stress Analysis" [23]. FEM which is the procedure to obtain numerical approximations for solid or fluid to the solution of the boundary value problems has been used widely in most engineering fields including the surface mounting as to provide better solder interconnect reliability and quality. The first step to do the FEM by numerical calculation is to identify the partial differential equation (PDE).

$u^{\prime \prime}(x)=f(x)$

Next, multiply the equation with $v(x)$ and then integrate at both sides.

$\int_{0}^{1} u^{\prime \prime}(x) v(x)=\int_{0}^{1} f(x) v(x)$

The left-hand side of the above equation can be reduced to,

$\left.u^{\prime}(x) v(x)\right|_{0} ^{1}-\int u^{\prime}(x) v^{\prime}(x)=\int f(x) v(x)$ 
After the weak form of integral has been set up, the discretization of the weak form takes place. This discretization functioned to convert the integral form to a set of matrices.

Early of the resurrection of the simulation for the reflow soldering process by using FEM, most of the researchers focussed on the thermal variation effect during the process which was considered as one of the main causes of solder defect. As in the research by Sarvar and Conway [24], they developed a predictive model as a tool that can improve the thermal distribution and temperature history during the process while for Mui et al., [25] they developed a numerical model to simulate the reflow soldering process while determining the stress and strain distribution which lastly brings to the further prediction of the solder reliability and Weide [26] which also simulating the reflow process via FEM has merge that two factors that influence the reliability of the solder which is the mechanical stress besides the thermal behaviour of the soldering process. The newest study on the simulation of soldering process via FEM was studied in the year 2017 where a model of the soldering process using an over-pressure convection oven was done and the heat transfer was calculated [27]. The model also used to predict the temperature distribution during the process.

In this latest 5 years, researchers are still keen on the numerical simulation of reflow soldering via FEM. Researcher used FEM simulation to study the IMC growth and the morphology of the IMC layer in certain testing condition such as in the investigation by Ghosh et al., [28] and Kunwar et al., [29] which study about the effect of stress and strain and the effect of interfacial heat and mass transfer which affecting the growth of IMC and its morphology while Maleki et al., [30] and Ma et al., [31] have studied about the hardening, growth and the interaction between the phase of growing IMC layer during the reflow process.

Most of the studies gave attention on the failure analysis which raised during the process such as the studies by Qin et al., [32] and Magnien et al., [33] which emphasize the FEM simulation on the defect analysis with the effect of different solder standoff height under the shear loading and the effect of IMC and the solder gap size on the tensile behaviour respectively while Le et al., [34] and Pin et al., [35] have done the FEM simulation on the thermo-mechanical effect under the thermal cycles. The use of FE modelling has improved the classical failure analysis method as the image and animation made by the FE software assisted a better understanding by visualizing the cause of the failure.

The defect is always connected to the reliability of the product. FE has become a significant tool to improve the design quality as to improve its reliability in various applications. In term of solder technology, the reliability is when the solder can withstand certain testing under specified conditions and time period without exceeding allowable failure levels. The use of FE modelling software such as the ABAQUS ${ }^{\circledR}$ and ANSYS $^{\circledR}$ in the reliability study of solder has been increased widely. As in the research by Amalu et al., [36] which developed FE simulation on the effect of the solder geometry and ambient parameters to the reliability of thermo-fatigue while Shen et al., [37] have studied about the thermomigration in solder during the heating process to its reliability.

\subsubsection{The simulation of nano-reinforced solder using finite element method}

To lower the experimental cost and the time taken for the experimental work, the simulation has been the best solution as the simulation provides a good understanding with its visualization and the image of the result. In recent years, the researcher gave attention on the addition of nanoparticles into the lead-free solder to increase its reliability. Thus, the simulation on the nano-reinforced solder during or after the soldering process increase vigorously as to avoid the high cost and the burning daylight experimental work. Researcher has added Lanthanum oxide nanoparticles [38], Ni-coated carbon nanotubes [39], reduced graphene oxide nanosheets (RGOS) [40], titanium oxide 
nanoparticles [41,42], copper nanoparticle [43] nickel and antimony [40] into the lead-free solder and they found that the reinforcement of those materials proved to give good increment in the solder mechanical properties and the quality of the IMC layer via experimental work and simulation. Most of the FE simulation has been used to simulate and demonstrate the mechanical testing for the validation purpose with the experimental result.

\subsection{Finite Volume Method to Simulate the Reflow Soldering Process}

The finite volume method (FVM) model has been proved to have a good capability of modelling fluid with high accuracy [44]. This method is used for solving partial differential equations that calculate the values of the conserved variables averaged across the volume. Starting from PDE under conservation form,

$\partial_{t} A(x, t)+\nabla \cdot F(x, t)=S(x, t)$

To obtain the balance equation from Eq. (4), integrate the above equation with $K \times\left[t^{(n-1)}, t^{(n)}\right]$ and using the divergence formula,

$$
\begin{aligned}
& \int_{K}\left(A\left(x, t^{(n)}\right)-A\left(x, t^{(n-1)}\right)\right) d x+\sum_{\sigma \in \varepsilon_{K}} \int_{t^{(n-1)}}^{t^{(n)}} \int_{\sigma} F(x, t) \cdot n_{K, \sigma}(x) d s(x) d t \\
& =\int_{t^{(n-1)}}^{t^{(n)}} \int_{K} S(x, t) d x d t
\end{aligned}
$$

The balance FV equation is,

$$
|K|\left(A_{K}^{(n)}-A_{K}^{(n-1)}\right)+\delta t^{(n)} \sum_{\sigma \epsilon \varepsilon_{K}}|\sigma| F_{K, \sigma}^{(n)}=\delta t^{(n)}|K| S_{K}^{(n)}
$$

From the studies that have been done before, most of the soldering process FVM simulation used to model the environment in the reflow oven which considers the gas flow in the oven [45-47]. Other research on the FVM simulation of the reflow soldering process is the investigation on the selfalignment phenomena of the different silver content lead-free solder during the process [48]. The Volume of Fluid (VOF) method was applied for the melting process.

\subsubsection{The simulation of nano-reinforced solder using finite volume method}

As described in the above section, FVM will be used in the modelling of the oven environment in most of the simulation for the reflow soldering process. As in the research by Haslinda et al., [21] which using titanium dioxide to be reinforced in SAC 305 solder, the FVM was used to model the surrounding oven condition. The nano-reinforced lead-free solder wetting process also can be simulated with FVM and it is solved with the multiphase model which is the volume of fluid (VOF).

\subsection{Lattice Boltzmann Method to Simulate the Reflow Soldering Process}

LBM simulation is a versatile method of fluid simulation [49] as it can mimic the fluid behaviour thus can easily simulate fluid system such as the fluid droplet and also can be used to simulate complex fluid structure such as the porous media which hardly to be done via other computational 
fluid dynamics (CFD) method. Eq. (7) shows the discretization of the Boltzmann equation with the Bhatnagar, Gross and Krook (BGK) approximation for the collision term.

$$
f\left(x+v_{i}, v_{i}, t+1\right)-f\left(x, v_{i}, t\right)+F\left(v_{i}\right)=\frac{1}{\tau}\left[f^{0}(n, u, \theta)-f\left(x, v_{i}, t\right)\right]
$$

In term of reflow soldering simulation, the researcher studied the effect of different bump orientations on the void formation via LBM simulation [49]. The results have found the predicted void locations during the process. Another study of LBM computational simulation by Abas et al., [50] has emphasized the effect of different solder bump arrangements on the flow front, pressure and velocity of the fluid which related to the solder bump damage was investigated. From this investigation, the researcher found that LBM is the only method that capable to capture the microvoid formation. The finding shows good agreement between the simulation and the experimental result.

\subsection{The Simulation of Nano-Reinforced Solder using Discrete Phase Method}

To see the trajectory of nanoparticles in a material is not an easy way via experimental work. There are several steps which need to be followed precisely so that the nanoparticles can be seen via an electron microscope. Simulation has made easier to see the trajectory of the nanoparticles via the animation provided when the simulation was done. The trajectory is calculated by integrating the particle force balance equation as in Eq. (8). Researchers have developed the DPM simulation to show the trajectory of titanium oxide $\left(\mathrm{TiO}_{2}\right)$ nanoparticles in the lead-free solder $[21,51]$.

$\frac{\delta u_{i}^{p}}{\delta t}=F d\left(u_{i}-u_{i}^{p}\right)+\frac{g_{i}\left(\rho_{p}-\rho\right)}{\rho_{p}}+\frac{F_{i}}{\rho_{p}}$

The drag force $F d$ is a function of the relative velocity and the $F_{i}$ is the additional forces such as the pressure gradient, thermophoretic, Brownian motion and others. The experimental work also has been done to validate the result of the simulation and it shows good agreement between them.

\subsection{Molecular Dynamic Simulation to Simulate the Reflow Soldering Process}

The simulation of the soldering process can be done also with an MD simulation. This MD simulation is mainly a method to study the atomic or molecular physical movement in a material. There are a lot of software package for MD simulation, including Large-scale Atomic/Molecular Massively Parallel Simulator (LAMMPS) [52], Chemistry at HARvard Macromolecular Mechanics (CHARMM) [53], GROningen MAchine for Chemical Simulations (GROMACS) [54], Nanoscale Molecular Dynamics (NAMD) [55], Assisted Model Building with Energy Refinement (AMBER) [56], Desmond [57], Tinker [58], DL_POLY [59], and others which can be used according to the simulation result needed. The MD simulation of lead-free solder during the reflow soldering process via the Modified Embedded Atom Method (MEAM) has been done before where the diffusion of Sn atoms and $\mathrm{Ag}$ atoms [52] has been studied. The result from the simulation shows that the diffusion did not occur between $\mathrm{Sn}$ and $\mathrm{Ag}$ atoms as the mixture of $\mathrm{Sn}$ and $\mathrm{Ag}$ were not enough as for the requirement of the solder during the low-temperature reflow soldering process. Later, the researcher has improved the simulation by increasing the reflow temperature to increase the activation energy of the atoms [60] and the finding shows that the interdiffusion of Sn and Ag atoms occur only at a higher 
temperature. Thus, MD simulation can show clearly how the atoms or molecules move and diffuse in a certain condition as in the above cases, the temperature act as the variable.

\section{Conclusions}

There is a lot of simulation method that can be used to simulate the soldering process that can be chosen according to the desired result. The best soldering process simulating method to find the better prediction of temperature profile and stress/strain distribution, study the IMC growth and its morphology and study on the defect analysis after mechanical testing is the FEM which is the best predictive tool for computational modelling. FVM is the best for simulating the fluid flow or the reflow oven inner condition and has been proved to have great capability to model the fluid with high accuracy. LBM is the best to simulate the fluid system as it can mimic the fluid behaviour thus make ease to simulate complex fluid structure. In the case of void in the solder, LBM is said to have the capability to capture the micro-void formation. To see the trajectory of particles in the solder, DPM simulation is the best method to choose while the MD simulation can show the behaviour of the atoms and molecule of solder and how they interact during the process.

\section{Acknowledgement}

The authors would like to thank Universiti Sains Malaysia, Penang, Malaysia, for the financial support through Research University Grant (RUI) 1001/ PMEKANIK/8014072.

\section{References}

[1] Lee, Ning-Cheng. Reflow soldering processes. Elsevier, 2002.

[2] Vianco, P. T., and Y. Feng. "Electronic Packaging: Solder Mounting Technologies." (2016). https://doi.org/10.1016/B978-0-12-803581-8.10099-2

[3] Yang, Dora. Comparison between wave soldering and reflow soldering. Techbriefs, 2018.

[4] Ma, Hongtao, and Jeffrey C. Suhling. "A review of mechanical properties of lead-free solders for electronic packaging." Journal of materials science 44, no. 5 (2009): 1141-1158. https://doi.org/10.1007/s10853-008-3125-9

[5] Cheng, Shunfeng, Chien-Ming Huang, and Michael Pecht. "A review of lead-free solders for electronics applications." Microelectronics Reliability 75 (2017): 77-95. https://doi.org/10.1016/i.microrel.2017.06.016

[6] Lee, A., and K. Nora. "Subramanian. Development of nano-composite lead-free electronic solders." Journal of Electronic Materials 34 (2005): 1400-1407. https://doi.org/10.1007/s11664-005-0197-z

[7] Tay, S. L., A. S. M. A. Haseeb, and Johan Mohd Rafie. "Effect of addition Cobalt nanoparticles on Sn-Ag-Cu lead-free solder." In 2010 12th Electronics Packaging Technology Conference, pp. 433-436. IEEE, 2010. https://doi.org/10.1109/EPTC.2010.5702678

[8] Liu, Ping, Xiaolong Gu, Haifeng Fu, and Yang Liu. "The effects of Cu nanoparticles addition in Sn-3.0 Ag-0.5 Cu solder paste on the microstructure and shear strength of the solder joints." In 2016 17th International Conference on Electronic Packaging Technology (ICEPT), pp. 852-855. IEEE, 2016. https://doi.org/10.1109/ICEPT.2016.7583264

[9] Nadia, Aemi, and A. S. M. A. Haseeb. "Understanding the effects of addition of copper nanoparticles to Sn-3.5 Ag solder." Soldering \& surface mount technology 23, no. 2 (2011): 68-74. https://doi.org/10.1108/09540911111120131

[10] Shang, Shengyan, Yanfeng Wang, Yunpeng Wang, Haitao Ma, and Anil Kunwar. "Enhancement of hardness of bulk solder by doping Cu nanoparticles at the interface of Sn/Cu solder joint." Microelectronic Engineering 208 (2019): 47-53. https://doi.org/10.1016/i.mee.2019.01.009

[11] Bukat, Krystyna, Marek Kościelski, Janusz Sitek, Małgorzata Jakubowska, and Anna Młożniak. "Silver nanoparticles effect on the wettability of Sn-Ag-Cu solder pastes and solder joints microstructure on copper." Soldering \& Surface Mount Technology 23, no. 3 (2012): 150-60. 
https://doi.org/10.1108/09540911111146908

[12] El-Daly, A. A., A. E. Hammad, A. Fawzy, and D. A. Nasrallh. "Microstructure, mechanical properties, and deformation behavior of Sn-1.0 Ag-0.5 Cu solder after Ni and Sb additions." Materials \& Design 43 (2013): 40-49. https://doi.org/10.1016/i.matdes.2012.06.058

[13] El-Daly, A. A., A. M. El-Taher, and T. R. Dalloul. "Enhanced ductility and mechanical strength of Ni-doped Sn-3.0 Ag0.5 Cu lead-free solders." Materials \& Design 55 (2014): 309-318. https://doi.org/10.1016/i.matdes.2013.10.009

[14] Tao, Q. B., L. Benabou, L. Vivet, V. N. Le, and F. B. Ouezdou. "Effect of $\mathrm{Ni}$ and Sb additions and testing conditions on the mechanical properties and microstructures of lead-free solder joints." Materials Science and Engineering: A 669 (2016): 403-416. https://doi.org/10.1016/j.msea.2016.05.102

[15] Yakymovych, A., P. Švec, L. Orovcik, O. Bajana, and H. Ipser. "Nanocomposite SAC solders: the effect of adding Ni and $\mathrm{Ni}-\mathrm{Sn}$ nanoparticles on morphology and mechanical properties of Sn-3.0 Ag-0.5 Cu solders." Journal of Electronic Materials 47, no. 1 (2018): 117-123. https://doi.org/10.1007/s11664-017-5834-9

[16] Chellvarajoo, Srivalli, M. Z. Abdullah, and C. Y. Khor. "Effects of diamond nanoparticles reinforcement into lead-free $\mathrm{Sn}-3.0 \mathrm{Ag}-0.5 \mathrm{Cu}$ solder pastes on microstructure and mechanical properties after reflow soldering process." Materials \& Design 82 (2015): 206-215. https://doi.org/10.1016/j.matdes.2015.05.065

[17] Chellvarajoo, Srivalli, M. Z. Abdullah, and Z. Samsudin. "Effects of Fe2NiO4 nanoparticles addition into lead free Sn$3.0 \mathrm{Ag}-0.5 \mathrm{Cu}$ solder pastes on microstructure and mechanical properties after reflow soldering process." Materials \& Design 67 (2015): 197-208. https://doi.org/10.1016/i.matdes.2014.11.025

[18] Gu, Yue, Xiuchen Zhao, Yi Li, Ying Liu, Yong Wang, and Zhenyu Li. "Effect of nano-Fe2O3 additions on wettability and interfacial intermetallic growth of low-Ag content $\mathrm{Sn}-\mathrm{Ag}-\mathrm{Cu}$ solders on $\mathrm{Cu}$ substrates." Journal of Alloys and Compounds 627 (2015): 39-47. https://doi.org/10.1016/i.jallcom.2014.12.024

[19] Salleh, MAA Mohd, S. D. McDonald, C. M. Gourlay, H. Yasuda, and Kazuhiro Nogita. "Suppression of Cu6Sn5 in TiO2 reinforced solder joints after multiple reflow cycles." Materials \& Design 108 (2016): 418-428. https://doi.org/10.1016/i.matdes.2016.06.121

[20] Li, Z. L., G. Y. Li, B. Li, L. X. Cheng, J. H. Huang, and Y. Tang. "Size effect on IMC growth in micro-scale Sn-3.0 Ag-0.5 Cu-0.1 TiO2 solder joints in reflow process." Journal of Alloys and Compounds 685 (2016): 983-991. https://doi.org/10.1016/i.jallcom.2016.06.295

[21] Haslinda, M. S., Aizat Abas, F. Che Ani, Azman Jalar, A. A. Saad, and Mohd Zulkifly Abdullah. "Discrete phase method particle simulation of ultra-fine package assembly with SAC305-TiO2 nano-reinforced lead free solder at different weighted percentages." Microelectronics Reliability 79 (2017): 336-351. https://doi.org/10.1016/j.microrel.2017.07.054

[22] Kanlayasiri, Kannachai, and Nadee Meesathien. "Effects of zinc oxide nanoparticles on properties of SAC0307 leadfree solder paste." Advances in Materials Science and Engineering 2018 (2018). https://doi.org/10.1155/2018/3750742

[23] Pradhan, Karan Kumar, and Snehashish Chakraverty. Computational Structural Mechanics. Chakraverty, (2019).

[24] Sarvar, Farhad, and Paul P. Conway. "A modelling tool for the thermal optimisation of the reflow soldering of printed circuit assemblies." Finite Elements in Analysis and Design 30, no. 1-2 (1998): 47-63. https://doi.org/10.1016/S0168-874X(98)00025-0

[25] Mui, Gary K., X-H. Wu, Kai X. Hu, C-P. Yeh, and Kral Wyatt. "Solder joint formation simulation and finite element analysis." In 1997 Proceedings 47th Electronic Components and Technology Conference, pp. 436-443. IEEE, 1997.

[26] Weide, Kirsten. "Impact of FEM simulation on reliability improvement of packaging." Microelectronics Reliability 39, no. 6-7 (1999): 1079-1088. https://doi.org/10.1016/S0026-2714(99)00153-5

[27] Esfandyari, Alireza, Bassim Bachy, Stefan Raithel, Aarief Syed-Khaja, and Joerg Franke. "Simulation Optimization and Experimental Verification of the Over-Pressure Reflow Soldering Process." In Procedia CIRP, vol. 62, pp. 565570. Elsevier, 2017. https://doi.org/10.1016/i.procir.2016.06.092

[28] Ghosh, Rituparna, Anwesha Kanjilal, and Praveen Kumar. "Effect of type of thermo-mechanical excursion on growth of interfacial intermetallic compounds in Cu/Sn-Ag-Cu solder joints." Microelectronics Reliability 74 (2017): 44-51. https://doi.org/10.1016/i.microrel.2017.05.011

[29] Kunwar, Anil, Bingfeng Guo, Shengyan Shang, Peter Råback, Yunpeng Wang, Jun Chen, Haitao Ma, Xueguan Song, 
and Ning Zhao. "Roles of interfacial heat transfer and relative solder height on segregated growth behavior of intermetallic compounds in Sn/Cu joints during furnace cooling." Intermetallics 93 (2018): 186-196.

https://doi.org/10.1016/j.intermet.2017.11.021

[30] Kunwar, Anil, Bingfeng Guo, Shengyan Shang, Peter Råback, Yunpeng Wang, Jun Chen, Haitao Ma, Xueguan Song, and Ning Zhao. "Roles of interfacial heat transfer and relative solder height on segregated growth behavior of intermetallic compounds in Sn/Cu joints during furnace cooling." Intermetallics 93 (2018): 186-196. https://doi.org/10.1016/j.intermet.2017.11.021

[31] Ma, H. R., A. Kunwar, S. Y. Shang, C. R. Jiang, Y. P. Wang, H. T. Ma, and N. Zhao. "Evolution behavior and growth kinetics of intermetallic compounds at Sn/Cu interface during multiple reflows." Intermetallics 96 (2018): 1-12. https://doi.org/10.1016/j.intermet.2018.01.022

[32] Qin, H. B., X. P. Zhang, M. B. Zhou, X. P. Li, and Y-W. Mai. "Geometry effect on mechanical performance and fracture behavior of micro-scale ball grid array structure $\mathrm{Cu} / \mathrm{Sn}-3.0 \mathrm{Ag}-0.5 \mathrm{Cu} / \mathrm{Cu}$ solder joints." Microelectronics Reliability 55, no. 8 (2015): 1214-1225. https://doi.org/10.1016/i.microrel.2015.05.013

[33] Magnien, J., G. Khatibi, M. Lederer, and H. Ipser. "Investigation of interfacial behavior in miniaturized solder interconnects." Materials Science and Engineering: A 673 (2016): 541-550.

https://doi.org/10.1016/i.msea.2016.07.060

[34] Benabou, Lahouari, Victor Etgens, and Quang Bang Tao. "Finite element analysis of the effect of process-induced voids on the fatigue lifetime of a lead-free solder joint under thermal cycling." Microelectronics Reliability 65 (2016): 243-254. https://doi.org/10.1016/j.microrel.2016.07.098

[35] Karayan, Ahmad Ivan, Deni Ferdian, Sri Harjanto, Dwi Marta Nurjaya, Ahmad Ashari, and Homero Castaneda. "Finite element analysis applications in failure analysis: Case studies." Finite Element Analysis-Applications in Mechanical Engineering, F. Ebrahimi, Ed. Rijeka: InTech (2012).

[36] Amalu, Emeka H., N. N. Ekere, M. T. Zarmai, and G. Takyi. "Optimisation of thermo-fatigue reliability of solder joints in surface mount resistor assembly using Taguchi method." Finite Elements in Analysis and Design 107 (2015): 1327. https://doi.org/10.1016/i.finel.2015.08.004

[37] Shen, Yu-An, Shiqi Zhou, Jiahui Li, King-Ning Tu, and Hiroshi Nishikawa. "Thermomigration induced microstructure and property changes in Sn-58Bi solders." Materials \& Design 166 (2019): 107619.

https://doi.org/10.1016/j.matdes.2019.107619

[38] Zhang, Liang, and Li-li Gao. "Interfacial compounds growth of SnAgCu (nano La2O3)/Cu solder joints based on experiments and FEM." Journal of Alloys and Compounds 635 (2015): 55-60. https://doi.org/10.1016/j.jallcom.2015.02.110

[39] Yang, Lizhuang, Wei Zhou, Yinghua Liang, Wenquan Cui, and Ping Wu. "Improved microstructure and mechanical properties for Sn58Bi solder alloy by addition of Ni-coated carbon nanotubes." Materials Science and Engineering: A 642 (2015): 7-15. https://doi.org/10.1016/i.msea.2015.06.080

[40] Peng, Yitian, and Kun Deng. "Fabrication of reduced graphene oxide nanosheets reinforced Sn-Bi nanocomposites by electro-chemical deposition." Composites Part A: Applied Science and Manufacturing 73 (2015): 55-62. https://doi.org/10.1016/i.compositesa.2015.03.006

[41] Li, Z. L., G. Y. Li, B. Li, L. X. Cheng, J. H. Huang, and Y. Tang. "Size effect on IMC growth in micro-scale Sn-3.0 Ag-0.5 Cu-0.1 TiO2 solder joints in reflow process." Journal of Alloys and Compounds 685 (2016): 983-991. https://doi.org/10.1016/j.jallcom.2016.06.295

[42] Shang, Shengyan, Anil Kunwar, Jinye Yao, Haitao Ma, and Yunpeng Wang. "Geometrical effects on growth kinetics of interfacial intermetallic compounds in Sn/Cu joints reflowed with Cu nanoparticles doped flux." Thin Solid Films 669 (2019): 198-207. https://doi.org/10.1016/i.tsf.2018.10.037

[43] Shang, Shengyan, Yanfeng Wang, Yunpeng Wang, Haitao Ma, and Anil Kunwar. "Enhancement of hardness of bulk solder by doping Cu nanoparticles at the interface of Sn/Cu solder joint." Microelectronic Engineering 208 (2019): 47-53.

https://doi.org/10.1016/j.mee.2019.01.009

[44] Ng, Fei Chong, Aizat Abas, Z. L. Gan, Mohd Zulkifly Abdullah, F. Che Ani, and M. Yusuf Tura Ali. "Discrete phase method study of ball grid array underfill process using nano-silica filler-reinforced composite-encapsulant with varying filler loadings." Microelectronics Reliability 72 (2017): 45-64.

https://doi.org/10.1016/i.microrel.2017.03.034

[45] Illes, Balazs, and Istvan Bako. "Numerical study of the gas flow velocity space in convection reflow 
oven." International Journal of Heat and Mass Transfer 70 (2014): 185-191.

https://doi.org/10.1016/j.ijheatmasstransfer.2013.10.075

[46] Kim, M. R., Y. K. Choi, G. B. Lee, I. Y. Chung, and J. D. Kim. "Thermal investigation of an infrared reflow furnace with a convection fan." In InterSociety Conference on Thermal Phenomena in Electronic Systems, I-THERM V, pp. 211 216. IEEE, 1996.

[47] Illés, Balázs. "Comparing 2D and 3D numerical simulation results of gas flow velocity in convection reflow oven." Soldering \& Surface Mount Technology 26, no. 4 (2014): 223-230. https://doi.org/10.1108/SSMT-07-2013-0016

[48] Najib, A. M., Mohd Zulkifly Abdullah, A. A. Saad, Z. Samsudin, and F. Che Ani. "Numerical simulation of selfalignment of chip resistor components for different silver content during reflow soldering." Microelectronics Reliability 79 (2017): 69-78. https://doi.org/10.1016/i.microrel.2017.10.011

[49] Abas, Aizat, Muhammad Hafifi Hafiz Ishak, Mohd Zulkifly Abdullah, F. Che Ani, and Soon Fuat Khor. "Lattice Boltzmann method study of bga bump arrangements on void formation." Microelectronics Reliability 56 (2016): 170-181. https://doi.org/10.1016/j.microrel.2015.10.014

[50] Abas, Aizat, Z. L. Gan, M. H. H. Ishak, M. Z. Abdullah, and Soon Fuat Khor. "Lattice Boltzmann method of different BGA orientations on I-type dispensing method." PloS one 11, no. 7 (2016). https://doi.org/10.1371/journal.pone.0159357

[51] Mukhtar, MA Fatah M., Aizat Abas, M. S. Haslinda, F. Che Ani, M. Z. Abdullah, Azman Jalar, and R. Ismail. "Discrete Phase Model (DPM) study of nano-reinforced Lead Free Solder Sn-3.0 Ag-0.5 Cu (SAC305)." In IOP Conference Series: Materials Science and Engineering, vol. 370, no. 1, p. 012067. IOP Publishing, 2018. https://doi.org/10.1088/1757-899X/370/1/012067

[52] Theng, Soong Guan, Khairulazhar bin Jumbri, and Mohd Dzul Hakim Wirzal. "Molecular dynamics simulation of membrane in room temperature ionic liquids." In AIP Conference Proceedings, vol. 1891, no. 1, p. 020133. AIP Publishing LLC, 2017. https://doi.org/10.1063/1.5005466

[53] Célerse, Frederic, Louis Lagardère, Etienne Derat, and Jean-Philip Piquemal. "Massively parallel implementation of Steered Molecular Dynamics in Tinker-HP: comparisons of polarizable and non-polarizable simulations of realistic systems." Journal of chemical theory and computation 15, no. 6 (2019): 3694-3709. https://doi.org/10.1021/acs.jctc.9b00199

[54] Theng, Soong Guan, Khairulazhar Jumbri, and Mohd Dzul Hakim Wirzal. "Membrane Simulation in Room Temperature Ionic Liquid and Oil using Molecular Dynamics." Journal of Advanced Research in Fluid Mechanics and Thermal Sciences 42, no. 1 (2018): 38-45.

[55] Dong, Hai, Lianhua Fan, Kyoung-sik Moon, C. P. Wong, and M. I. Baskes. "Molecular dynamics simulation of lead free solder for low temperature reflow applications." In Proceedings Electronic Components and Technology, 2005. ECTC'05., pp. 983-987. IEEE, 2005.

[56] Yadav, Mahima, and Shikha Khandelwal. "Homology modeling and molecular dynamics dimulation study of $\beta$ carbonic anhydrase of Ascaris lumbricoides." Bioinformation 15, no. 8 (2019): 572-578. https://doi.org/10.6026/97320630015572

[57] Ong, Ernest ES, and Jong-Leng Liow. "The temperature-dependent structure, hydrogen bonding and other related dynamic properties of the standard TIP3P and CHARMM-modified TIP3P water models." Fluid Phase Equilibria 481 (2019): 55-65. https://doi.org/10.1016/j.fluid.2018.10.016

[58] Stalker, Megan R., James Grant, Chin W. Yong, L. A. Ohene-Yeboah, Timothy J. Mays, and Stephen C. Parker. "Molecular simulation of hydrogen storage and transport in cellulose." Molecular Simulation (2019): 1-10. https://doi.org/10.1080/08927022.2019.1593975

[59] Dong, Hai, Lianhua Fan, Kyoung-sik Moon, C. P. Wong, and M. I. Baskes. "Molecular dynamics simulation of lead free solder for low temperature reflow applications." In Proceedings Electronic Components and Technology, 2005. ECTC'05., pp. 983-987. IEEE, 2005.

[60] Dong, Hai, Lianhua Fan, Kyoung-sik Moon, C. P. Wong, and M. I. Baskes. "MEAM molecular dynamics study of lead free solder for electronic packaging applications." Modelling and Simulation in Materials Science and Engineering 13, no. 8 (2005): 1279. https://doi.org/10.1088/0965-0393/13/8/006 